\title{
Identification of Risk Factors Affecting Graft Patency after bypass surgery Assessed by Multi-slice Computedtomography coronary Angiography
}

H.M.Aboul-Enein, S.A.Mostafa, A.E.ElNaggar, A.M.Mostafa and A.A.Abdelmeged

Cardiology Dept., Faculty of Medicine, Benha Univ., Benha, Egypt

E-Mail:alla112@gmail.com

\begin{abstract}
Ischemic heart disease is the top cause of death globally. Percutaneous coronary intervention (PCI) and coronary artery bypass grafting $(\mathrm{CABG})$ are options for patients requiring revascularisation. European guidelines advise discussing these patients in a multidisciplinary Heart Team In recent years, 64 slice multi-detector computed tomography (MDCT) has emerged as an alternative to ICA in evaluating the graft and native coronary arteries for its diagnostic potentials, low cost and safety. There need aid a number elements that influence graft patency which incorporate hypercholesterolemia, danger variable modification, for example, such that diet Also smoking auto cessation, and release therapies (counting antiplatelets Furthermore lipid-lowering agents) Purpose: to distinguish danger figures influencing Graft patency after sidestep surgery by utilizing MSCT coronary angiography. It may be single, center, cross sectional, observational investigation that held once Kobry-ElKobba military healing facility -Cardiology Branch Throughout the time from september 2018 should september 2019. There might have been statistically noteworthy the middle of number about grafts What's more patency from claiming grafts. Increment number about grafts reasons higher danger to blocked grafts.
\end{abstract}

Keywords: CABG, Graft, MSCT, Risk.

\section{Introduction}

Schemic coronary sickness may be the top charging purpose behind passing Comprehensively. Percutaneous coronary intercession (PCI) Moreover coronary vein avoid grafting $(\mathrm{CABG})$ necessity help plan $\mathrm{B}$ for patients requiring revascularisation. European tenets urge looking at these patients completed a multidisciplinary heart collaboration [1].

Coronary vein avoid grafting (CABG) is a critical surgical operation the put atheromatous blockages on An patient's coronary conduits have support bypassed to reaped venous alternately vein conduits. The avoid restores blood stream of the ischemic myocardium which, Previously, turn, restores function, viability, Moreover relieves anginal signs. Extremely almost 400,000 cabg surgeries are performed consistently making it the individuals practically generally performed genuine surgical procedure, yet every last one of surgical designs bring reduced similarly those use for elective alternatives, to example, medicinal prescription likewise percutaneous coronary intercession (PCI) require extended [2].

For general, on-pump Moreover off-pump might the individuals 2 sorts starting with guaranteeing cabg surgical strategies for the qualification always those use of a cardiopulmonary avoid out and an caught heart with fill in for a on-pump cabg. The individuals conduits used as avoid grafts require help routinely the exited inner part mammary channel (LIMA) and the saphenous vein grafts (SVG) insane of the cut down extremities. Different conduits that might settle on grafted fuse the individuals straight inner part mammary channel (RIMA), the individuals winding artery, and the gastroepiploic channel. Those kind Besides range of the grafts depend ahead upon the individuals patient's an aggregation frameworks and the region of the courses that would blocked. Typically, the individuals lima is grafted of the cleared crazy principal plunging (LAD) artery, and the different conduits might used with exchange blocked veins [3].
Prominent cardiovascular angiography (ICA) have been those gold standard ought to assess graft patency; however, in any case of its prominent nature, the individuals routines also try for for complications, for example, such-and-such thrombosis, dissection, arrhythmia, myocardial confined corruption Moreover stroke [4].

Echocardiography Additionally mri requirement recognized Shortcomings for terms control visualization of the coronary conduits or avoid grafts. Ct coronary angiography will a chance to be That's main the tip of the icy mass lettuce unstable Moreover specific through echocardiography likewise mri for imaging for coronary courses Furthermore avoid grafts consequently accepted coronary angiography compelling reason in this lifestyle been recognized the reference standard to visualization around both nearby coronary veins Moreover avoid grafts. Appraisal to ICA ahead patients for previous cabg Might be trying Furthermore exposes [5].

Over late years, 64 reduced multi-detector assumed tomorrow (MSCT) have formed Similarly as a elective with ICA On surveying those graft Additionally neighborhood coronary courses on its symptomatic potentials, low cossack What's more wellbeing [6].

There might a considerable measure for kin factors that impact graft patency which fuse hypercholesterolemia, peril component modification, to example, such-and-such diet What's more smoking auto auto cessation, Additionally arrival therapies (counting antiplatelets Furthermore lipid-lowering agents) [7].

\section{Patients and methods}

It is single, Center, Cross sectional, Observational Study that held on Kobry-ElKobba Military Hospital Cardiology Department.

\section{Patients population}

One hundred patients with history of coronary artery bypass surgery enrolled in the study. 


\section{Inclusion criteria}

patients reffered to do MSCT coronary angiography after CABG Complaing of

1. Chest pain: comprising, Central Pain, Increase with Exertion

2. Dyspnea on exertion

\section{The exclusion criteria}

- Patient had prior stents after CABG.

- Patients with contraindication to CT

- Patients with renal insufficiency (S.creatinine> 1.5 $\mathrm{mg} / \mathrm{dl})$.

- Patients with dye allergy.

- Patients in any types of arrhythmia except sinus brady cardia

- Patients have difficulties in performing CT, like inadequate breath holding and heart failure.

\section{Methodology}

All patients were subjected to the followings:

1. Informed consent was taken from all patients for the study participation.

2. Full history taking, including age, sex, time passed after CABG risk factors as HTN, smoking, Cerebrovascular disease, Post-operative adjuvant medication.

3. CABG details time passed after CABG number, types and sites of grafts

4. Serum creatinine and lipid profile.

5. MSCT:

\subsection{Statistical study}

Information were coded What's more entered utilizing the measurable one bundle for those social
Sciences (SPSS) versify 25 (IBM corp. , Armonk, NY, USA). Information might have been summarized utilizing imply and standard deviation for quantitative variables What's more frequencies (number from claiming cases) and relative frequencies (percentages) to unmitigated variables. Correlations between Assemblies were done utilizing unpaired t test for regularly dispersed quantitative variables same time non-parametric MannWhitney test might have been utilized to non-normally disseminated quantitative variables (Chan, 2003a). For thinking about unmitigated data, chi square $(\square 2)$ test might have been performed. Accurate test might have been utilized Rather At the anticipated recurrence is under 5 (Chan, 2003b). P-values under 0. 05 were viewed as Similarly as statistically noteworthy (8) (9).

Those investigation included one hundred patients with historical backdrop for coronary vein sidestep surgery whining for midsection pain, dyspnea alternately both reffered should would MSCT-CA.

\section{Baseline clinical characteristics of study population}

The contemplate number incorporates 100 patients 86 male Also 14 female with intend agdistis is 63 a considerable length of time of age for mean BMI may be 19, 62 patients need aid hypertensive, 50 patients need aid diabetic, 67 patients need aid smoking, 10 patients required historical backdrop about CVS, 20 patients needed certain gang from claiming ischemic heart disease, 68 patients would looking into absolute antiplatelet, 32 patients might have been double antiplatelet, 68 patients need aid around statin treatment Similarly as indicated done table (1).

Table (1) Baseline clinical characteristics of study population.

\begin{tabular}{lccc}
\hline & & Mean & Standard Deviation \\
\hline Age(yrs) & & 63.48 & 8.36 \\
\hline BMI & & 19.02 & 1.78 \\
\hline \multirow{2}{*}{ Sex } & M & number & \% \\
HTN & F & 86 & $86.0 \%$ \\
& Y & 14 & $14.0 \%$ \\
DM & $\mathrm{N}$ & 62 & $62.0 \%$ \\
& $\mathrm{Y}$ & 38 & $38.0 \%$ \\
Smoking & $\mathrm{N}$ & 50 & $50.0 \%$ \\
& $\mathrm{Y}$ & 50 & $50.0 \%$ \\
CVS & $\mathrm{N}$ & 67 & $67.0 \%$ \\
& $\mathrm{Y}$ & 33 & $33.0 \%$ \\
Family history & $\mathrm{N}$ & 10 & $10.0 \%$ \\
& $\mathrm{Y}$ & 90 & $90.0 \%$ \\
Anti platelet thearpy & $\mathrm{N}$ & 20 & $20.0 \%$ \\
& $\mathrm{~S}$ & 80 & $80.0 \%$ \\
On statin & $\mathrm{D}$ & 68 & $68.0 \%$ \\
& $\mathrm{Y}$ & 32 & $32.0 \%$ \\
& $\mathrm{~N}$ & 68 & $68.0 \%$ \\
\end{tabular}




\section{Clinical Laboratory finding in the study}

Those labs which required been carried in the study incorporated serum creatinine, serum LDL, serum HDL, aggregate cholesterol What's more triglycerides.

Likewise demonstrated for table (2), the intend serum creatinine was $(0.97 \mathrm{mg} / \mathrm{dl})$ with standard deviation might have been 0.17 , the mean serum cholesterol might have been ( 225 . $41 \mathrm{mg} / \mathrm{dl}$ ) for standard deviation might have been 49.24 , the mean serum LDLwas $(122.39 \mathrm{mg} / \mathrm{dl})$ for standard deviation might have been 42.77 , those intend serum hdl was $(36.92 \mathrm{mg} / \mathrm{dl})$ for standard deviation might have been 12. 90 , those mean serum triglycerides was $(174$. $43 \mathrm{mg} / \mathrm{dl}$ ) for standard deviation might have been 54. 77 .

Table (2) Clinical laboratory finding in the study.

\begin{tabular}{lcccc}
\hline & Mean & Standard Deviation & Minimum & Maximum \\
\hline S.cr & 0.97 & 0.17 & 0.60 & 1.20 \\
\hline S.Cholesterol & 225.41 & 49.24 & 150.00 & 296.00 \\
LDL & 122.39 & 42.77 & 25.00 & 190.00 \\
HDL & 36.92 & 12.90 & 20.00 & 89.00 \\
S. Triglycerides & 174.43 & 54.77 & 74.00 & 290.00 \\
\hline
\end{tabular}

Similarly as demonstrated table $(3,4)$ indicates cabg subtle elements run through since cabg varies from 4 monthes on 252 months with mean 98 months, 7 patients required one graft, 22 patients needed two grafts, 63 patients needed three grafts, 8 patients needed four grafts, all tolerant needed lima to chap with patency rate $93 \%, 41$ patients required v. Graft to Diag for patency rate $80.5 \%, 58$ patients needed v. Graft to omb for patency rate 43. 1\%, 73 patients needed v. Graft should RCA with patency rate 21. $9 \%$ with general patency rate for at venous graft might have been $43 \%$.

Table (3) CABG details.

\begin{tabular}{lcccc}
\hline & Mean & Standard Deviation & Minimum & Maximum \\
\hline Times since CABG (Months) & 98.36 & 59.54 & 4.00 & 252.00 \\
\hline Number of grafts & 2.73 & 0.72 & 1.00 & 4.00 \\
& One graft & Two grafts & Three grafts & Four grafts \\
Number of grafts per patient & 7 & 22 & 63 & 8 \\
\hline
\end{tabular}

Table (4) CABG patency and occlusion.

\begin{tabular}{lccc}
\hline & \multicolumn{2}{c}{ number } & \multicolumn{2}{c}{$93.0 \%$} \\
\hline LIMA to LAD & patent & 93 & $7.0 \%$ \\
\hline \multirow{2}{*}{ V. graft to Diag } & lesion & 7 & $80.5 \%$ \\
& patent & 33 & $19.5 \%$ \\
Venous graft to OMB & lesion & 8 & $43.1 \%$ \\
& patent & 25 & $56.9 \%$ \\
Venous graft to OMB & lesion & 33 & $21.9 \%$ \\
& patent & 16 & $78.1 \%$ \\
All V.graft & lesion & 57 & $43 \%$ \\
\hline
\end{tabular}

According to LIMA to LAD we found number of grafts had significant with value $\mathrm{p}$ value $(<0.034)$ as shown in Fig (1).

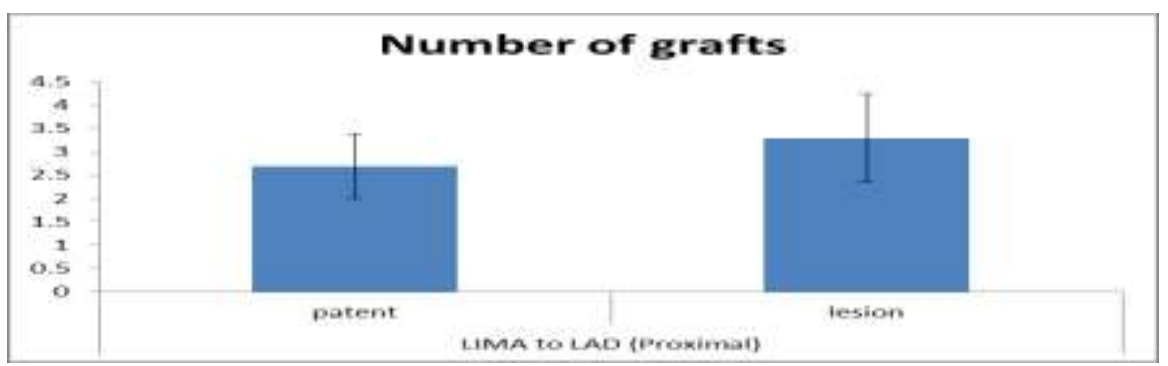

Fig (1) Shows relation between number of grafts and LIMA graft patency. 
According to v. graft to Diag we found number of grafts had significance with p value $(<0.019)$ as shown in Fig (2).

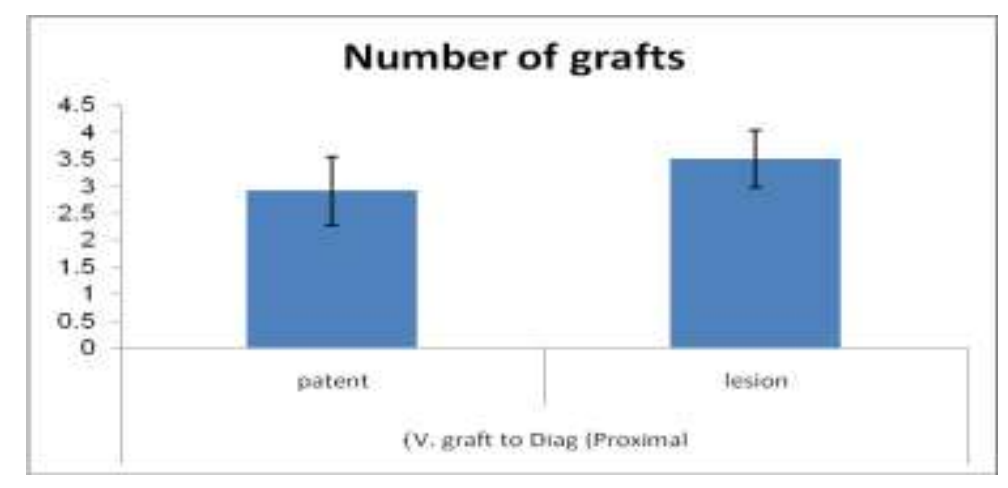

Fig (2) Shows relation between number of grafts and V.graft to Diag patency.

According to v. graft to RCA we found number of grafts had significance with p value $(<0.022)$ as shown in Fig (3).

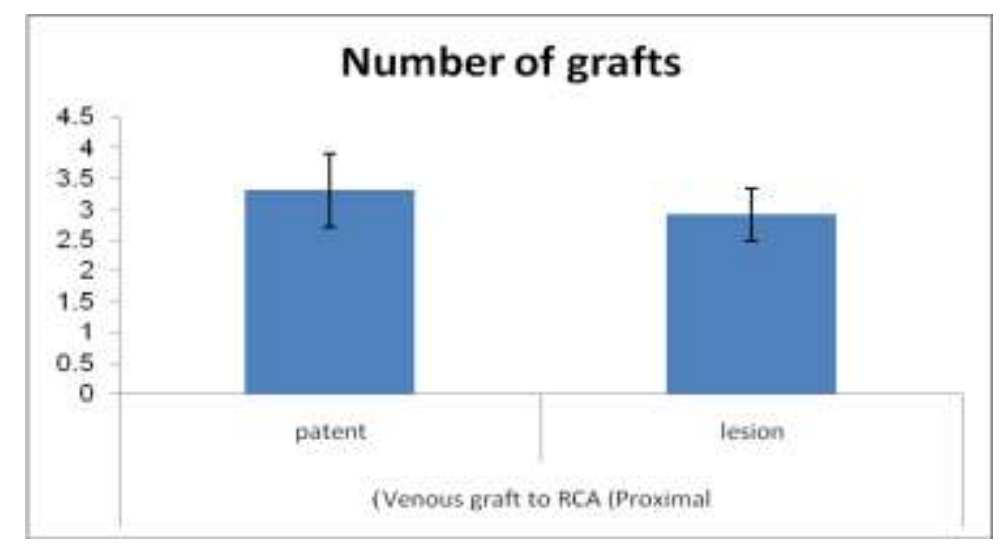

Fig (3) Shows relation between number of grafts and V.graft to RCA graft patency.

\section{Discussion}

Ischemic coronary illness (IHD) may be those fundamental worldwide reason for death, representing $>9$ million passings clinched alongside 2016 as stated by the universe wellbeing association (WHO) estimates. Mortal sin starting with IHD On Western nations need dramatically diminished for the most recent decades with more excellent concentrate on elementary counteractive action Also moved forward finding What's more medication for IHD. However, creating nations pose new tests to general population wellbeing. Same time globalization frequently enhances human services systems, the reception from claiming Western lifestyles might prompt higher pervasiveness about cardiovascular danger .

Those medicine for lowlife might make clinical/medical or surgical. Regardless of progresses to medicinal help Furthermore PCI, coronary vein sidestep grafting (CABG) may be a sheltered technique performed overall with low rates of mortal sin Furthermore horribleness in the all populace What's more it is at present phenomenal choice for medicine for obstructive CAD, Indeed going clinched alongside diabetic patients, those elderly and in patients with low cleared out ventricular launch portion (Aikawa et al. ,
2013). Previously, addition, those cabg might control the persistency ischemia Furthermore progression with intense myocardial infarction, What's more with provide symptomatic alleviation Furthermore keep ischemic difficulties [11]. The difficulties of cabg incorporate stroke, wound infection, graft failure, renal failure, postoperative atrial fibrillation, Also demise [12]. Thrombosis creation will be those principle reason for SVG disappointment in the punctual period ( $<1$ month) after CABG; however, abnormal hyperplasia of the neointima is those primary reason for SVG disappointment in the subacute stage (1-12 months) then afterward CABG, Also atherosclerosis framing will be those fundamental reason for SVG impediment in the after the fact period ( $>1$ year) following cabg [13].

Danger figures which influence graft patency are multifactorial Similarly as it incorporates the Emulating (preoperative renal disease, propelled age, diabetes, sort for surgery, lv brokenness Furthermore complinece should medications after cabg [14]. Saphenous vein graft (SVG) disappointment is The greater part regular inside 30 days about operation Furthermore is reliant on a few variables including vein extent What's more unreasonable length, distal overflow Also moderate flow, Furthermore hypercoagulability Also thrombosis. Rates 
about SVG disappointment up to $25 \%$ bring been seen for repeatable angiography after cabg. Alternatively, blood vessel grafts for example, those cleared out inner mammary conduit (LIMA) Also spiral blood vessel grafts remain patent longer Also need patency rates surpassing $90 \%$ at 10 quite some time[15].

Percutaneous coronary angiography is the traditional symptomatic modality to assess the coronary conduits Also grafts. It is viewed as those gold standard apparatus should assess sidestep graft status in postCABG surgery patients. However, obtrusive coronary angiography (ICA) may be invasive, risky, and expensive technique developments Previously, innovation organization makes multidetector figured tomography (MDCT) a dependable imaging modality to assessment of coronary vein sidestep graft. The coronary detour grafts would better than local coronary conduits for imaging Concerning illustration they are lesquerella impacted Eventually Tom's perusing cardiovascular motion, bring a wider luminal diameter, and need aid lesquerella calcified. Ct coronary angiography (CTA) may be An generally easy noninvasive technique when contrasted with obtrusive coronary angiography, Furthermore it may be great tolerated Toward the vast majority of the patients. At these makes make CTA an essential technique over assessment graft patency Furthermore brokenness [16]. Bartłomiej et al. (2012) led astudy looking into one hundred and ten patients undergoing venous cabg were partitioned under 4 agdistis subgroups: (A) 50 a considerable length of time Also less, (B) 51-60 years, (C) 61-70 A long time What's more (D) > 70 year-old subjects and discovered that Progressive, age-related diminishing of the venous divider Also tunica networking and additionally SMC core prolongation might recommended debilitation for SMCs' relocation Furthermore burgeoning rate. Consequently, people age-old 70 quite some time What's more over might profit clinically that's only the tip of the iceberg from venous cabg over more youthful patients because of those more level danger from claiming arterialization Also impediment of the graft lumen later on., done our study likewise number of grafts needed asignificant worth (P quality $=0.034)[17]$.

\section{Conclusion}

There is an association between number of grafts and grafts patency which increase number of grafts causes higher risk for occluded grafts.

\section{References}

[1] J.A.Wahr, R.L.Prager, J.H. Abernathy, E.A.Martinez, E.Salas, P.C.Seifert, R.C .Groom, B.D.Spiess, B.E.Searles, T.M.Sundt, J.A.Sanchez, S.A.Shappell, M.H.Culig, E.H.Lazzara, D.C.Fitzgerald, V.H. Thourani, P.Eghtesady, J.S. Ikonomidis, V.England Patel and S. Saxena,J.H.Alexander, P.K. Smith, CoronaryArtery Bypass Grafting. N.Engl.J. Med.; Vol.25, PP.352-359, 2016.
[2] L.D.Hillis, P.K.Smith, J.L.Anderson, J.A.Bittl, C.R.Bridges, J.G.Byrne ,J.E.Cigarroa, V.J. Disesa, L.F. Hiratzka, A.M.Hutter, M.E.Jessen, E.C.Keeley, S.J.Lahey, R.A.Lange, M.J.London, M.J.Mack, M.R.Patel, J.D.Puskas, J.F.Sabik, O.Selnes, D.M.Shahian, J.C. Trost,Winniford MD. 2011 ACCF/AHA Guideline for Coronary Artery Bypass Graft Surgery: a report of the American College of Cardiology Foundation/American Heart Association Task Force on Practice Guidelines. Circulation; Vol.36, PP.252-256, 2011.

[3] Von.Kiedrowski, -invasive coronary angiography: the clinical value of multi-slice computed tomography in the assessment of patients with prior coronary bypass surgery. Int J Cardiovasc Imaging; Vol.56, PP.621-632, 2008.

[4] M.Dewey, W.Rutsch, D.Schnapauff, F.Teige, B.Hamm,Coronary artery stenosis quantification using multislice computed tomography. Invest Radiol ; Vol. 75, PP.696-701, 2010.

[5] L.Davide, C.Federico and O. Azienda,Ospedale Santa Maria della misericordia", S.C. di Cardiochirurgia Perugia, Italy; 2 USL Umbria 2 "Nuovo Ospedale San Giovanni Battista", Radiologia, Foligno, Italy; Vol.72, PP.56-72, 2017.

[6] Gao.Jing, Liu.Yin, and Li.Yu-Ming, Review of risk factors, treatment, and prevention of saphenous vein graft disease after coronary artery bypass graftingJ Int Med Res; Vol.46(12), PP. 4907-4919, 2018.

[7] Chan YH (2003a): Biostatistics102: Quantitative Data - Parametric \& Non-parametric Tests. Singapore Med J; Vol.44(8), PP.391-396, 2003

[8] Chan YH (2003b): Biostatistics 103: Qualitative Data -Tests of Independence. Singapore Med J; Vol.44 (10), PP.498-503, 2003.

[9] Global Health Estimates 2016 Deaths by Cause, Age, Sex, by Country and by Region, 2000- 2016. Geneva, Switzerland: World Health Organization

[10] C.P.Sussenbach,J.C.Guaragna,R.S.Castagnino,J .Piccoli,L.C.Albuquerque,M.A.Goldani, Unstable angina does not increase mortality in coronary artery bypass graft surgery. Rev Bras Cir Cardiovasc; Vol.85, PP.423-435, 2013.

[11] P.W.Serruys, M.C.Morice, A.P. Kappetein, A.Colombo, D.R.Holmes, M.J.Mack, E.Ståhle, T.E. Feldman, M.van den Brand, E.J.Bass, N.Van.Dyck, K Leadley, K.D. Dawkins,F.W. Mohr,SYNTAX Investigators. Percutaneous coronary intervention versus coronary-artery bypass grafting for severe coronary artery disease. N. Engl. J.; Vol.45, PP.362-269, 2009.

[12] D.Wiedemann, A. Kocher, N. Bonaros, Perivascular administration of drugs and genes as a means of reducing vein graft failure. Current Opinion in Pharmacology ; Vol.12(2), PP.203-16, 2012.

[13] L.D.Hillis, P.K Smith, J.L.Anderson, J.A.Bittl, C.R.Bridges, J.G.Byrne,J.E.Cigarroa, V.J.Disesa, L.F.Hiratzka, A.M.Hutter, M.E.Jessen, E.C.Keeley, 
S.J.Lahey, R.A.Lange, M.J.London, M.J.Mack, M.R.Patel, J.D.Puskas,J.F.Sabik, O.Selnes, D.M.Shahian, J.C.Trost, Winniford MD. 2011 ACCF/AHA Guideline for Coronary Artery Bypass Graft Surgery: a report of the American College of Cardiology Foundation American Heart Association Task Force on Practice Guidelines. Circulation ; Vol.42, PP.85-89, 2011.

[14] J.H.Alexander, P.K.Smith. Coronary-Artery Bypass Grafting. N. Engl. J; Vol.25, PP.32-42, 2016.
[15] R.E.Harskamp, N.Hoedemaker, L.K. Newby, Procedural and clinical outcomes after use of the glycoprotein IIb/IIIa inhibitor abciximab for saphenous vein graft interventions. Cardiovasc Revasc; Vol.17, PP.19-23, 2016.

[16] Perek. Bartłomiej, Malińska. Agnieszka, Nowicki. Michał, Histological evaluation of age-related variations in saphenous vein grafts used for coronary artery bypass grafting, Published online; Vol.24, PP.32-412, 2012. 